Discussion Paper No. 02-33

\title{
A Note on Pricing and Efficiency in Print Media Industries
}

\author{
Ulrich Kaiser
}

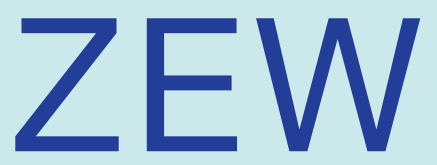

Zentrum für Europäische Wirtschaftsforschung $\mathrm{GmbH}$

Centre for European Economic Research 
Discussion Paper No. 02-33

\title{
A Note on Pricing and Efficiency in Print Media Industries
}

\author{
Ulrich Kaiser
}

Download this ZEW Discussion Paper from our ftp server:

ftp://ftp.zew.de/pub/zew-docs/dp/dp0233.pdf

Die Discussion Papers dienen einer möglichst schnellen Verbreitung von neueren Forschungsarbeiten des ZEW. Die Beiträge liegen in alleiniger Verantwortung der Autoren und stellen nicht notwendigerweise die Meinung des ZEW dar.

Discussion Papers are intended to make results of ZEW research promptly available to other economists in order to encourage discussion and suggestions for revisions. The authors are solely responsible for the contents which do not necessarily represent the opinion of the ZEW. 


\section{Non-technical summary}

Print media markets, that is newspaper and magazine markets, have a very specific feature: actors are faced by two demand curves, the demand for the print medium itself and the demand for advertising space contained in the print medium. These demand curves are interrelated since advertising demand is mainly determined by circulation and print medium purchasers value advertising - at least to some extent. This interrelationship leads to the empirically well documented phenomenon that print media firms charge cover prices that are below marginal production cost.

The demand interrelationship weakens competitive concerns with respect to the recent concentration of print media industries. This paper shows that the demand interrelationship causes print media firms to charge cover prices that are below cover prices in the case of non-existence of the demand interrelationship. It also establishes the conditions under which print media firms price below marginal cost. Unlike earlier literature that makes somewhat unrealistic assumptions regarding print media firms' influence on the advertising market, I show that cover prices in monopoly are always higher than under perfect competition. 


\title{
A Note on Pricing and Efficiency in Print Media Industries
}

\author{
ULRICH KAISER* \\ Centre for European Economic Research, Harvard University \\ and National Bureau of Economic Research
}

May 14, 2002

\begin{abstract}
Actors on print media markets face two different (and interrelated) demand curves: the demand for copies and the demand for advertising space. This paper develops a realistic, yet simple, model of print media industries. In contrast to earlier studies, it takes into account that print media firms can neither set advertising space nor its price. A main finding of this paper is that competitive concerns regarding recent concentrations in print media industries are likely to be overstated since a print media firms' cover pricing is limited by its feedback on advertising demand.
\end{abstract}

Keywords: print media, advertising, product pricing

JEL classification: D4, L4

*Address: Ulrich Kaiser, Centre for European Economic Research, Harvard University and National Bureau of Economic Research, 1050 Massachusetts Avenue, Cambridge, MA 02138, USA; phone: +617 588-1420, fax: +617 868-5023, email: ukaiser@nber.edu; http://www.zew.de/en/mitarbeiter/mitarbeiter.php3?action=mita\&kurz=uka. Change in address from July 1, 2002: Ulrich Kaiser, Faculty of Social Sciences, Dept. of Economics, University of Southern Denmark, Campusvej 55, DK-5230 Odense M, Denmark; phone: +45 6550-3363, fax +45 6593-5692, email: uka@sam.sdu.dk.

I am indebted to the VolkswagenStiftung for funding this research within the 'Empirical Economics - Program of Fellowships for German Researchers in the United States' program and to the NBER, especially to Ernst R. Berndt, for hosting me during the academic year 2001/2002. 


\section{Introduction}

The effects of media concentration on newspaper and magazine prices has remained high on the economic policy agenda for decades. A particularly well documented instance of highly concentrated print media markets is Australia, where only a handful players act on the newspaper market. ${ }^{2}$ Although Australia presumably is an extreme case, many other countries, such as Italy with the Berlusconi empire or Germany, the U.K. and the U.S. (as documented by Wagner, 1982) nurse their own national champions. Having an in terms of interpretability simple but still realistic model of the effects of media concentration on prices at hand hence appears to be useful from an economic policy point of view.

Print media markets come with one very special feature: actors are faced by two different and interrelated demand curves, the demand for the print medium itself and the demand for advertising space contained in the print medium. This leads to a 'demand interdependence' (Rosse, 1978; as cited by Chaudhri, 1998, p. 60) in the sense that changes in the circulation of the print medium induces changes in the demand for advertising space and vice versa, at least if consumers value advertising as it has been demonstrated by numerous studies (Kaiser 2002; Rosse 1970; Rysman 2000).

In a recent game-theoretical contribution to the discussion about market conduct in print media industries, Chaudhri (1998) sets up a model where print media firms are quantity setters both in the circulation and advertising dimension. While the former appears to be very reasonable, assuming that print media firms can set advertising space seems not to meet well with reality, even though Chaudhri (1998) is consistent with almost the entire earlier literature that also assumes that print media firms are either price setters or quantity setters in both market dimensions (Blair and Romanao 1993; Bucklin et al. 1989; Corden 19521953; Dertouzos and Trautman 1990; Ferguson 1983; Merrilees 1983, 1998; Rosse 1967,1970; Thompson 1989). Instead, it seems more reasonable to think of print media firms to be faced by a demand curve for advertising space that is 'out there in the market' in the sense that advertisers have a willingness to pay for advertising space that depends upon the circulation of the print medium.

More recent papers that look at the market for advertising space such as Berry and Waldfogel (1999), who analyze radio broadcasting, Rysman (2002), who investigates yellow pages, and Kaiser (2002), who looks at womens' magazines, straightforwardly make adverting dependent on the number of consumers 'produced' by media firms. The idea that advertising depends on the number of readers produced by the print medium is presumably best illustrated by the functional form assumption for inverse advertising demand for advertising cho-

\footnotetext{
${ }^{2}$ Studies on the Australian newspaper industry include Chaudhri (1998) and Merrilees (1983, 1998).
} 
sen by Berry and Waldfogel (1999) as well as by Kaiser (2002). Both papers pick a constant elasticity framework where the inverse demand for advertising is given by

$$
p_{i}^{a}=\lambda_{i}\left(q_{i}^{c}\right)^{\eta},
$$

where $\eta$ denotes the inverse price elasticity of advertising demand - or what Corden (1952-1953, p. 182) termed 'circulation elasticity' —, $q_{i}^{c}$ denotes the number of printed copies and $p_{i}^{a}$ denotes the price charged for an advertising page by print medium $i$. The parameter $\lambda$ is a demand-shift variable that might for example capture the extent to which the print media firm focuses on specific consumer groups.

The key idea followed in the present paper is that newspapers cannot set advertising apace (and neither advertising price) but that they rather determine circulation, thereby defining inverse demand for advertising.

Although the present paper takes a very different initial model setup, it comes to conclusions that are in line with Chaudhri (1998). First, the condition under which print media firms charge cover prices below marginal production cost is qualitatively the same as in Chaudhri. Second, the demand interdependence between the market for print copies and the market for advertising space also is qualitative the same as in Chaudhri. Third, I find that cover prices are higher under monopoly than under perfect competition. One result is different compared to existing studies, in particular to Chaudhri, who establishes the conditions under which there might be welfare gains from moving from perfect competition to monopoly because advertising clients may gain from monopolization. This main difference is due to the simple fact that there is only one decision variable in my model (instead of two in Chaudhri, who assumes that print media firms set both circulation and advertising pages): circulation. In my model, media firms decrease quantities under monopoly, thereby reducing the price they can charge for advertising space.

By and large, the overlap in the findings suggest that even if earlier empirical studies on print media markets (Dertouzos and Trautman 1990; Ferguson 1983; Merrilees 1983; Rosse 1970; Thompson 1989) might not have reasonably specified the market for advertising space, the qualitative conclusions reached by these studies might not be far off qualitatively from what would have been obtained had these studies taken a more realistic model of advertising demand.

\section{The model}

The major flaw of the earlier existing literature on print media pricing is that it is assumed that print media firms can determine the level of advertising. This is, however, very unlikely to be the case since the number of advertising pages 
per issue depends on the attractiveness of the print medium from the advertising clients' perspective. Its attractiveness in turn mainly depends on the number of copies sold. Consequently, it seems more realistic to consider the number of copies sold to consumers as the only variable at the discretion of the print medium. The print medium firms' profit maximization problem hence is: ${ }^{3}$

$$
\max _{q_{i}^{c}} \Pi_{i}=\left(p_{i}^{c}\left[q_{i}^{c}\right]-m c_{i}\right) q_{i}^{c}+p_{i}^{a}\left[q_{i}^{c}\right] q_{i}^{a}-F_{i}
$$

where $p_{i}^{c}$ denotes the cover price of print medium $i, m c_{i}$ denotes marginal costs accruing from producing one copy of the print medium and $q_{i}^{a}$ denotes the number of advertising pages per print medium issue. The term $F_{i}$ denotes fixed production cost.

The next two subsections derive the corresponding first-order conditions for profit maximization under monopoly and perfect competition and provide interpretations of the results.

\subsection{The monopoly solution}

Under monopoly, the profit-maximizing first-order condition is

$$
\frac{\partial \Pi_{i}}{\partial q_{i}^{c}}=p_{i}^{c}+\frac{\partial p_{i}^{c}}{\partial q_{i}^{c}} q_{i}^{c}-m c_{i}+\frac{\partial p_{i}^{a}}{\partial q_{i}^{c}} q_{i}^{a}=0
$$

so that

$$
p_{i}^{c}=m c_{i}-\underbrace{\underbrace{\frac{\partial p_{i}^{c}}{\partial q_{i}^{c}} q_{i}^{c}}_{\begin{array}{c}
\text { markup } \\
\text { deterioration }
\end{array}}-\underbrace{\frac{\partial p_{i}^{a}}{\partial q_{i}^{c}} q_{i}^{a}} .}_{\begin{array}{c}
(+) \\
\text { 'usual', } \\
\text { markup }
\end{array}}
$$

The first-order condition can hence be decomposed into their 'usual' markup term, $\partial p_{i}^{c} / \partial q_{i}^{c}$, and a 'markup deterioration', $\partial p_{i}^{a} / \partial q_{i}^{c} \cdot q_{i}^{a}$. That is, print media firms cannibalize the 'usual' markup in order to increase demand for advertising space: charging a lower price induces an increasing magazine demand which in turn raises the prices for advertising space.

Theorem 1: Magazine prices are smaller if the network effect from advertising demand is taken into account.

\footnotetext{
${ }^{3}$ Note that an analogous model can be set up for price-setting games. I expose a quantity setting game here for coherence with the earlier literature, in particular for coherence with Chaudhri (1998). See Kaiser (2002) for a treatment of a price-setting game.
} 
Proof: Setting $\partial p_{i}^{a} / \partial q_{i}^{c} \cdot q_{i}^{a}=0$, that is ignoring the network effect, leads to the usual price-equals-marginal-cost-plus-markup equation:

$$
p_{i}^{c}=m c_{i}-\frac{\partial p_{i}^{c}}{\partial q_{i}^{c}} q_{i}^{c}
$$

Comparing Equation (5) to Equation (4) proofs Theorem 1.

Theorem 1 shows that fears regarding monopolization of newspaper and magazine industries might be overstated since the print medium firms' strategies are restricted by the feedback of cover pricing on advertising demand.

Theorem 2: Magazines charge cover prices below marginal costs if (i) advertising revenues are large relative to the revenues from selling the print medium, (ii) the elasticity of advertising prices with respect to print media circulation is high and (iii) the demand for the print medium is price elastic.

Proof: From Equation (4) we know that $p_{i}^{c}-m c_{i}=-\partial p_{i}^{c} / \partial q_{i}^{c} q_{i}^{c}-\partial p_{i}^{a} / \partial q_{i}^{c} q_{i}^{a}$. Hence, $p_{i}^{c}<m c_{i}$ iff $-\partial p_{i}^{c} / \partial q_{i}^{c} q_{i}^{c}-\partial p_{i}^{a} / \partial q_{i}^{c} q_{i}^{a}<0$. Rewriting the latter in terms of elasticities leads to

$$
\underbrace{-\frac{1}{\eta_{q_{i}^{c}, p_{i}^{c}}}}_{\begin{array}{c}
\text { inverse price } \\
\text { elasticity of } \\
\text { print media } \\
\text { demand }
\end{array}}<\underbrace{\underbrace{}_{\eta_{p_{i}^{a}, q_{i}^{c}}}}_{\begin{array}{c}
\text { advertising } \\
\text { prices w.r.t. } \\
\text { circulation }
\end{array}} \quad \underbrace{\frac{q_{i}^{a} p_{i}^{a}}{q_{i}^{c} p_{i}^{c}}}_{\begin{array}{c}
\text { advertising sales } \\
\text { ratio }
\end{array}}
$$

which restates Theorem 2 .

Theorem 2 is very intuitive: if consumers are highly price sensitive, charging a lower price has a large impact on advertising sales. The magnitude of the negative incentive to charge high copy price depends on the sensitivity of advertising prices with respect to circulation, weighted by the ratio of magazine sales to advertising sales. This suggest that one might worry least about print media industry concentration in markets where print media consumers are very price sensitive.

Indeed, it is conventional wisdom that newspapers are sold below marginal production cost (Blair and Romano 1993; Wagner 1981). Kaiser (2002) shows that this is, quite unsurprisingly, also the case for magazine markets. Theorem 2 establishes the condition under which below-marginal cost pricing occurs. 


\subsection{The solution under perfect competition}

Under perfect competition, the demand for the print medium is perfectly elastic. Price hence equals marginal costs plus the network effect:

$$
p_{i}^{c}=m c_{i}-\frac{\partial p_{i}^{a}}{\partial q_{i}^{c}} .
$$

Theorem 3: Print media prices are always smaller than marginal cost in the case of perfect competition.

Proof: The proof is trivial from inspection of Equation (7).

The intuition behind Theorem 3 is simple: under perfect competition, and under disregard of the network effect, the print media firms' 'usual' markup is zero. If network effects are present, the print media firm is given an incentive to price below marginal cost because it can recoup the losses from producing the print media by selling advertising space.

Theorem 4: Print media prices are smaller under perfect competition than under monopoly.

Proof: The proof is trivial from comparing Equation (4) and Equation (7).

This is the main difference to earlier studies, and this difference arises from my different assumptions regarding firms' decision variables; while earlier studies assume that print media firms have command over both the advertising and the printed copy market, there is only one decision variable in my model. In my framework, advertising prices are determined by circulation so that lower circulation leads to lower advertising prices. This implies that advertisers are 'equally well off' in either case (monopoly and perfect competition) as advertising price automatically adjust via the reaction in circulation.

\section{Conclusion}

The print media market has one specific feature: market actors are faced by two demand curves, the demand for the print medium and the demand for advertising space contained in the print medium. This demand interdependence between advertising and circulation has important effects on firms' strategic behavior and on economic policy. In particular, it might pay off from the print medium firms' perspective to price below marginal cost since low cover prices induce a higher circulation and thus a higher demand for advertising.

In this paper I set up a simple, yet realistic, model of the print media industry. I demonstrate the effects on the demand interdependence of print media firms' 
strategies and establish the conditions under which print media firms price below marginal production cost.

From an economic policy point of view, the print media market presumably is a market where we have to worry least about negative effects to consumers from market concentration since the interrelation between the advertising market and the print medium market forecloses excessive pricing. 


\section{References}

Berry, S.T. and J. Waldfogel, 1999, Free entry and social inefficiency in radio broadcasting, RAND Journal of Economics 30(3), 397-420.

Blair, R.D. and R.E. Romano, 1993, Pricing decisions of the newspaper monopolist, Southern Economic Journal 59(4), 721-732.

Bucklin, R.E., R.E. Caves and A.W. Lo (1989), Games of survival in the US newspaper industry, Applied Economics 21, 631-649.

Chaudhri, V., 1998, Pricing and efficiency of a circulation industry: the case of newspapers, Information Economics and Policy 10, 59-76.

Corden, W.M., 1952-1953, The maximisation of profit by a newspaper, The Review of Economic Studies 20(3), 181-190.

Dertouzos, J.N. and W.B. Trautmann, 1990, Economic effects of media concentration: estimates from a model of the newspaper firm, The Journal of Industrial Economics 39(1), 1-14.

Ferguson, J.M., 1983, Daily newspaper advertising rates, local media crossownership, newspaper chains, and media competition, Journal of Law and Economics 26(3), 635-654.

Kaiser, U., 2002, Optimal cover prices and the effects of website provision on advertising and magazine demand, Harvard University mimeo.

Merrilees, W.J., 1983, Anatomy of a price leadership challenge: an evaluation of pricing strategies in the Australian newspaper industry, The Journal of Industrial Economics 31(3), 291-311.

Merrilees, W.J., 1998, Anatomy of a price leadership challenge: an evaluation of pricing strategies in the Australian newspaper industry (Edward Elgar, Northampton).

Thompson, R.S., 1989, Circulation versus advertiser appeal in the newspaper industry: an empirical investigation, The Journal of Industrial Economics 37(3), 259-271.

Rosse, J.N., 1967, Daily newspapers, monopolistic competition, and economies of scale, The American Economic review 57(2), Papers and Proceedings (May, 1967), 522-533.

Rosse, J.N., 1970, Estimating cost function parameters without using cost data: illustrated methodology, Econometrica 38(2), 256-275. 
Rosse, J.N., 1978, The evolution of one newspaper cities, Studies in Industry Economics No. 56, Dept. of Economics, Stanford University.

Rysman, M., 2000, Competition between networks: a study of the market for yellow pages, Boston University mimeo. 